\title{
ARTE RUPESTRE Y CÓDIGOS ESPACIALES: UN CASO DE ESTUDIO EN CHILE CENTRAL
}

\author{
ROCK ART AND SPATIAL CODES: A CASE OF STUDY IN CENTRAL CHILE
}

\author{
Andrés Troncoso ${ }^{1}$, Felipe Criado-Boado ${ }^{2}$ y Manuel Santos-Estévez ${ }^{2}$
}

\begin{abstract}
A partir de un enfoque teórico-metodológico basado en la Arqueología del Paisaje, exploramos la organización espacial de un sitio de arte rupestre en Chile central en busca de las estructuras que ordenan la distribución de las manifestaciones. Esta aproximación nos permite reconocer la presencia de un conjunto de códigos espaciales básicos, que definen el emplazamiento de los bloques grabados a partir de una organización que combina la dualidad, tripartición y cuatripartición. Con su identificación, se propone que estos códigos materializan en el espacio una forma de pensamiento propia al mundo andino, discutiéndose sus implicancias para la arqueología y prehistoria de Chile Central.
\end{abstract}

Palabras claves: arte rupestre, estructuras espaciales, pensamiento andino, Chile central.

Using Landscape Archaeology as a theoretical and methodological framework, we explore the spatial organization of a rock art site in Central Chile in search of the structures that order the distribution of engravings in the site. We recognize the presence of a group of spatial codes, which define the placement of the carved blocks through a system that combines duality, tripartition, and quadripartition. By identifying this organization system, we propose that these codes materialize in space some structural principles of Andean thought. We discuss the implications of that idea for the archaeology and prehistory of Central Chile.

Key words: Rock art, spatial structures, Andean thought, Central Chile.

Uno de los ámbitos de investigación que más proyecciones ha entregado en las últimas décadas para la comprensión del arte rupestre ha sido la variable espacial. Centrados en reconocer asociaciones económicas, funcionales y/o simbólicas con el entorno circundante, diferentes perspectivas han discutido la naturaleza inmueble de esta materialidad a nivel regional (p.ej., Chippindale y Nash 2004; Nash 2000; Nash y Chippindale 2002; Santos y Troncoso 2005; Tilley 1991). Sin embargo, hace ya varias décadas, y previo a esta revalorización del arte rupestre, Leroi-Gouhran $(1983,1994)$ planteó la existencia de estructuras particulares que definían la sintaxis y asociaciones de los diseños rupestres al interior de las cuevas paleolíticas. Si bien varias de sus proposiciones han sido criticadas a la luz de nuevas investigaciones, sus planteamientos abrieron las puertas para considerar la posibilidad de que códigos espaciales particulares se materializaran al interior de un sitio, respondiendo la distribución de los diseños a un patrón particular y en caso alguno aleatorio.

En este trabajo discutimos la posibilidad de existencia de códigos espaciales al interior de un sitio de arte rupestre en la cuenca superior del río Aconcagua, Chile central. Para tales efectos, esbozamos un conjunto de planteamientos teóricos que nos permiten acceder a este ámbito, los que se enmarcan en un modelo de investigación teórico-metodológico nacido desde la Arqueología del Paisaje (Cobas 2003; Cobas y Prieto 1998; Criado 1993, 1999, 2000a, 2000b; Santos 1998; Villoch 1998).

En particular, a partir del reconocimiento de estos códigos que estructuran la organización espacial de un sitio de arte rupestre, se discuten las implicancias teórico-metodológicas de su identificación en el registro arqueológico, para posteriormente efectuar una interpretación del sitio por la presencia de estos códigos, evaluando sus implicancias para la comprensión de las sociedades prehispánicas de Chile central.

\section{Arte Rupestre y Paisaje: de las Relaciones a los Códigos}

Los recientes y múltiples desarrollos dentro de la Arqueología del Paisaje han reconocido y enfatizado la comprensión social, cultural, histórica, política y

\footnotetext{
1 Departamento de Antropología, Universidad de Chile. Ignacio Carrera Pinto 1045, Nuñoa, Santiago, Chile. atroncos@uchile.cl

2 Instituto de Ciencias del Patrimonio (Incipit-CSIC). Instituto de Estudios Gallegos, San Roque 2, 15704 Santiago de Compostela, España. felipe.criado-boado@iegps.csic.es; manuel.santos@cchs.csic.es
} 
experiencial del espacio, discutiendo sus múltiples imbricaciones con variados procesos y dimensiones sociales (p.ej., Bender 1998; Bender y Winter 2001; Moore 2005; Tilley 1994, 2004).

Sin embargo, en cada una de ellas se ha relegado a un segundo plano el hecho que las actividades producidas en el espacio se organizan de forma coherente con la representación ideal del mundo que tiene un grupo social (Criado 1999, 2000a; Godelier 1989). En efecto, reconocemos que bajo toda experiencia y uso del espacio existe un sistema de representación que lo monitorea y lo constituye como arquitectura, por lo que no es posible pensar lo uno sin lo otro (Criado 1999, 2005). Sugerimos, entonces, que es factible reconstruir esta representación cultural del espacio a través del "análisis de la interrelación entre el mundo, el entorno artificial y los productos físicos de las prácticas sociales" (Criado 1999:10), en busca de los códigos que regulan la inscripción espacial del registro.

El reconocimiento de estos códigos espaciales posibilita un acercamiento a la comprensión de las formas en que las distintas sociedades han conceptualizado y organizado su espacio, a la vez que su identificación se constituye en un elemento central para la posterior interpretación arqueológica, en cuanto a través de ella podemos avanzar en la entrega de un contenido específico. En efecto, a través de un método de trabajo propuesto por uno de los autores (Criado 1999, 2005), se define un proceder arqueológico que, basado en el reconocimiento de estos principios estructurales, posibilita un acercamiento al sentido de este código a partir de un horizonte de inteligibilidad particular basado en un patrón de racionalidad antropológico ${ }^{1}$ (sensu Criado 2000b, 2005). Comenzando con un análisis formal procedemos a la deconstrucción del registro arqueológico para su posterior descripción, dando cuenta de los códigos y regularidades observadas entre los distintos tipos de registro material, para así pasar a la interpretación y síntesis que construye significación sobre los procesos históricos y sociales a partir de un modelo antropológico específico (el que se identifica como "cuatripartición andina") que funciona como el patrón de racionalidad desde el que se habría constituido el sentido original del registro (Criado 1999, 2000a, 2005).

En el caso particular del arte rupestre, reconocemos la presencia de tres niveles inclusivos de análisis (Troncoso 2008): el micro, referido al bloque; el semimacro, correspondiente al sitio arqueológico, y el macro, relacionado con la región. Es en estos distintos ámbitos donde la factibilidad de reconocer códigos es posible, pero también requiere cada uno de ellos un acercamiento metodológico particular fundado en el análisis formal.

En este caso, nuestro interés descansa en la identificación de tales códigos espaciales a nivel semimacro, es decir, al interior del sitio. Ahí creemos que tal estructuración se puede abordar a partir de dos aspectos básicos: (i) la distribución espacial de los bloques y (ii) la distribución de los diseños al interior del sitio.

Los bloques con imágenes constituyen una totalidad que entran en relaciones sintácticas y espaciales entre ellos y el entorno circundante, quedando como muestra fidedigna todas aquellas piedras que no fueron modificadas con arte rupestre. A través de su lógica espacial y sus relaciones con el espacio en el que se insertan, los grabados rupestres construyen una arquitectura particular que materializa códigos espaciales específicos. No es posible considerar un sitio de arte rupestre como una entidad compuesta sólo por rocas con imágenes, sino que su totalidad se estructura a partir de estas sintaxis espaciales con otros elementos que se incluyen en su interior, tales como rocas sin grabados o cambios en el relieve en el que se disponen los soportes (Troncoso 2008).

El estudio de estas estructuras espaciales se basa, por tanto, en análisis formales espaciales que reconocen la necesidad de una organización al interior de los sitios de arte rupestre, pero separándose de las rígidas implicancias interpretativas de oposiciones binarias universales que debilitaron las proposiciones de Leroi-Gouhran (1983, 1994).

\section{Arte Rupestre en Cerro Paidahuen}

La presente investigación concierne a la cuenca superior del río Aconcagua, Chile central. En particular, nos referimos al sitio cerro Paidahuen o Tapihue, cerro-isla emplazado en la ribera norte del río Aconcagua y cercano a la actual ciudad de Los Andes (Figura 1).

Este cerro se define por su gran magnitud, alcanzando una longitud superior a $1 \mathrm{~km}$ en su eje norte-sur y una altura de $125 \mathrm{~m}$ sobre las amplias terrazas fluviales que se ubican a sus pies. Ocupa una superficie total cercana a $1.383 .564 \mathrm{~m}^{2}(2.534 \mathrm{~m}$ en un eje norte-sur y $546 \mathrm{~m}$ en un eje este-oeste). Este cerro presenta dos características particulares: 

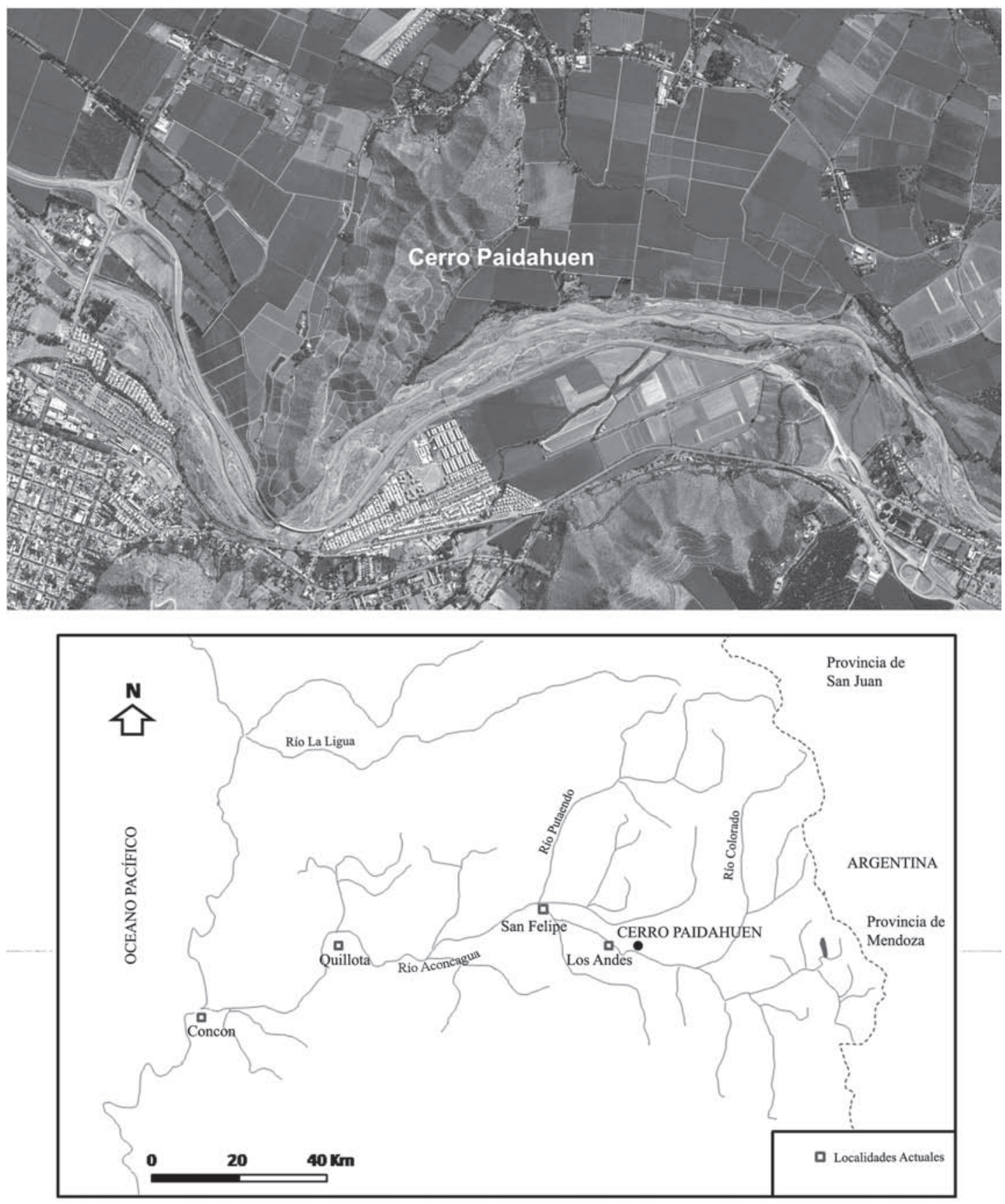

Figura 1. Mapa del área de estudio con indicación del cerro Paidahuen. Map of the study area indicating the location of Paidahuen hill. 
A
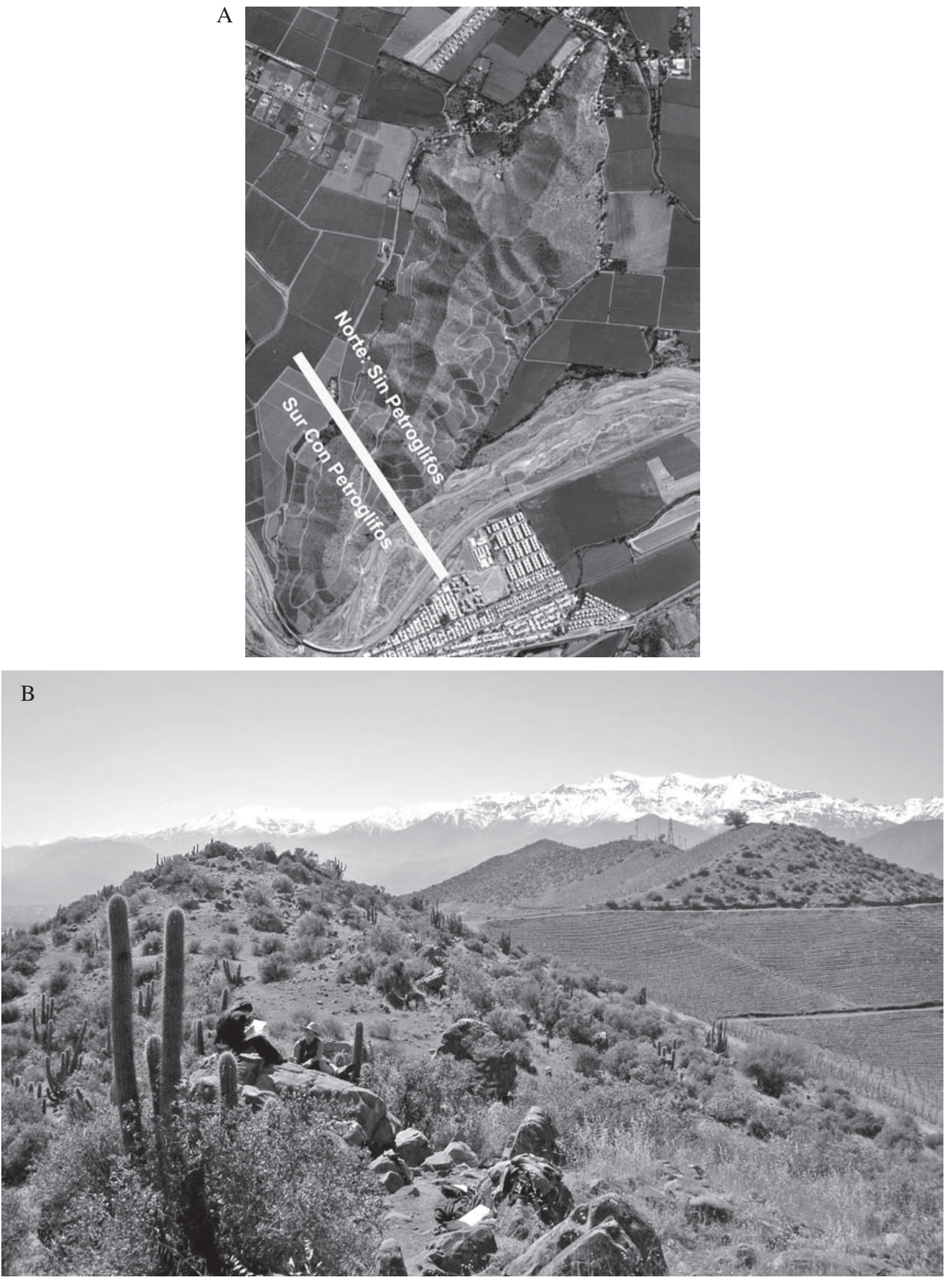

Figura 2. (a) mapa del sitio Paidahuen con indicación del eje norte-sur; (b) Visión desde el sur con inflexión del cerro que origina el eje de separación en dos mitades.

(a) Map of the Paidahuen site showing the North-South axis; (b) View from the South of slope break which gives rise to the axis of separation between two halves. 
primero, estar compuesto por múltiples promontorios que se alternan en su cima; y, segundo, por encontrarse una inflexión en su tercio sur que se define por un desplazamiento del cuerpo y cumbre del cerro levemente hacia el este, dando la apariencia visual de corresponder a dos cerros distintos unidos por un portezuelo (Figuras 2a, 2b).

Los trabajos en el cerro han permitido reconocer un total de 211 bloques con grabados rupestres. Por sus atributos formales a nivel de las figuras, ordenación en el soporte y estilo tecnológico, estos bloques son adscritos a los Estilos I y II del arte rupestre de la cuenca superior del río Aconcagua (Troncoso 2005), atribuidos a los períodos Intermedio Tardío (1.000-ca. 1.440 d.C.) y Tardío o Incaico (ca. 1.440-ca. 1.530 d.C.), respectivamente ${ }^{2}$.

Los diseños rupestres presentan una clara primacía de figuras esquemáticas y una baja representación de antropomorfos y zoomorfos (Mostny y Niemeyer 1985; Troncoso 2005, 2006). Se contabilizó un mínimo número de figuras de 1.294, de las cuales $1.209(93,4 \%)$ son de carácter no figurativo y $85(6,6 \%)$ corresponden a antropomorfos o zoomorfos.

Los diseños se disponen sobre rocas de tipo andesíticas que se encuentran distribuidas de manera regular por todo el cerro Paidahuen. Estos bloques rocosos son de un tamaño homogéneo y entregan a los creadores de arte rupestre diferentes superficies para la realización de grabados, quienes en cada petroglifo debieron efectuar dos decisiones: primero, qué roca marcar; y, segundo, qué cara de la roca intervenir. Esto nos permite indicar que la producción de arte rupestre en el sitio no se vio limitada ni por la disponibilidad de bloques rocosos (existen más de 600), ni por las superficies que componen las diferentes caras de cada roca.

Metodológicamente, los trabajos en terreno consideraron el relevamiento de cada uno de los bloques de arte rupestre a partir de fichajes de figuras, panel y bloque rocoso (Troncoso 2006). Se registró, también, la distribución espacial de las rocas con grabados, las orientaciones de los paneles, el número de caras con figuras que presentaba cada piedra, las condiciones de visibilidad de las rocas y de sus paneles (sensu Criado 1999), emplazamiento en el relieve y, en la medida que la variabilidad de los diseños lo permitió, su distribución al interior del sitio.

\section{Estructuración Espacial del sitio Cerro Paidahuen}

Los bloques con arte rupestre se distribuyen en la ladera y distintos promontorios de la cumbre del cerro. A la vez, su distribución se define por una ordenación particular en donde es posible diferenciar y segregar seis concentraciones de bloques con grabados. Cada una de estas concentraciones es una unidad discreta en sí, separada de las otras, lo que genera una organización espacial basada en la alternancia de espacios con contenido (rocas con grabados) y espacios vacíos (rocas sin grabados).

Cada una de estas concentraciones presentaba características similares, que venían dadas por una organización de tipo circular definida por la existencia de uno o dos bloques de carácter complejo al interior de cada conjunto, caracterizados por tener una alta cantidad de diseños grabados y diferentes caras de la roca intervenidas, y una serie adicional de soportes no-complejos, definidos por un menor número de diseños y generalmente tener sólo una cara de la roca grabada (Troncoso 2006). Se observa otra similitud entre los conjuntos, en las orientaciones de los bloques: $68,2 \%$ de las caras grabadas de los bloques se orienta hacia el norte.

No obstante la uniformidad existente en las diferentes concentraciones, el emplazamiento de cada una de ellas se basa en tres principios espaciales que organizan la distribución de los bloques dentro del sitio (dualidad, tripartición y cuatripartición), siendo posible identificar cinco estructuraciones particulares.

\section{Primera estructuración espacial: dualidad}

Al considerar la distribución de los bloques grabados en el cerro, se observa una primera ordenación espacial de tipo dual basada en la oposición entre la mitad norte y la sur. Del total de los 211 bloques con grabados, 210 se ubican en el área sur del cerro, por lo que se observa una notable ausencia de grabados en el sector norte (Figura 2a). Esta dicotomía norte:sur: ausencia:presencia de petroglifos, es más significativa si consideramos que la mitad sur abarca sólo un $20 \%$ del cerro Paidahuen, y que, en el restante $80 \%$ de espacio libre de petroglifos, hay más de 300 bloques factibles de ser grabados y que no lo fueron. 
Esta oposición no descansa sólo en la frecuencia de los soportes, sino que se asienta en un rasgo particular del cerro: la ya mencionada inflexión que genera un efecto visual particular, cual es que el cerro se vea desplazado desde el sur. Este efecto produce un quiebre en el eje visual lineal que ordena las distintas cimas en este sector del cerro, dando la apariencia que las cumbres del área norte fuesen parte de otro relieve (Figuras 2a, 2b).

De esta manera, se crea un eje visual que aprovecha la flexión del cerro y la presencia de un portezuelo entre uno y otro sector para marcar el eje divisor del espacio. Siguiendo la orientación de este portezuelo, se instala un eje oblicuo que separa una y otra mitad, y que de este modo ancla la dicotomía anterior en un elemento material del paisaje. Hemos definido, previamente, este rasgo del paisaje como expresión de una "estética de la alteridad" (Troncoso 2007), siguiendo los planteamientos de Van de Guchte (1999), y que se reencuentra en diferentes sitios de la cuenca superior del río Aconcagua, tales como los de la zona de Campos de Ahumada y Casa Blanca (Troncoso 2009).

\section{Segunda estructuración espacial: dualidad-2}

Una segunda estructura se produce al considerar únicamente la zona del cerro que presenta soportes de arte rupestre. Si revisamos la distribución espacial de los soportes rocosos, así como su relación con las formas del cerro, nos encontramos con la presencia de seis concentraciones particulares e independientes de grabados (Figura 3).

Si relacionamos estas concentraciones con su disposición en el cerro, así como sus condiciones de visibilidad y emplazamiento, apreciamos que el sector sur con petroglifos se desdobla, a su vez, en dos mitades. Una primera mitad constituida por las concentraciones I y II, ubicadas más al norte, y que se define por: (i) localización de los petroglifos en su ladera oeste, (ii) condiciones de visibilidad cerrada, pues desde ahí tan sólo se accede visualmente a los cuadrantes noroeste y suroeste de la zona y (iii) disposición en un sector bajo del cerro, que reproduce simplemente su disposición en laderas (Figura 3a).

En contraposición, la mitad sur del cerro, donde se encuentran las concentraciones III a VI, se define por: (i) localización de los petroglifos en la cumbre y ladera este del cerro, (ii) condiciones de visibilidad amplia, que permiten un manejo visual del entorno de $360^{\circ}$, y (iii) disposición de los bloques en un sector alto del cerro (Figura $3 \mathrm{~b}$ ).

En este segundo nivel encontramos, de nuevo, una primacía de la mitad sur respecto a la norte.

\section{Tercera estructuración espacial: cuatripartición}

La mitad sur del cerro, además de desdoblarse en la anterior dicotomía norte-sur, se desdobla de nuevo según un eje este-oeste. En efecto, las ocupaciones rupestres en el oeste del cerro se ubican en la mitad norte del sitio (concentraciones I y II), mientras que los petroglifos en el lado este se disponen claramente en su mitad sur (concentraciones III a VI) (Figuras 3 y 4).

La articulación de estos dos conjuntos reproduce en la organización espacial del cerro Paidahuen un patrón cuatripartito basado en un juego de opuestos espaciales que permite definir cuatro cuadrantes: noroeste, noreste, suroeste y sureste, donde encontramos que el cuadrante noroeste tiene mayor registro que su opuesto noreste, y el sureste uno mayor que el suroeste. Esto genera por lo tanto un patrón de opuestos simétricos que se establecen tanto en un eje horizontal (este-oeste) como vertical (norte-sur), dando origen a un patrón cuatripartito (Figura 4).

\section{Cuarta estructuración espacial: dualidad}

Al considerar el relieve y la altura relativa del arte rupestre en la mitad sur del sitio, las concentraciones III a VI se emplazan en pequeñas cumbres a lo largo de la cima del cerro.

Aquí nos encontramos con que la concentración III se dispone en un sector alto, la IV en un sector bajo en relación con la III, la $\mathrm{V}$ en un sector alto en relación con IV, pero en un sector bajo en relación con VI. VI se encuentra, por ende, en un sector alto. En una organización lineal tendríamos entonces un sistema que se definiría como alto (III)-bajo (IV)-alto (V)-muy alto (VI), lo que posibilitaría construir una diferenciación de nuevo entre dos mitades, una norte, donde encontramos III y IV, y luego una mitad sur con V y VI, lo que podríamos volver a traducir según los términos relativos de cada una de estas zonas a una oposición entre alto (III): bajo (IV): bajo (V): alto (VI), generando de nuevo una organización dual fundada en un sistema de opuestos y su desdoblamiento (Figuras 5 y 6). 


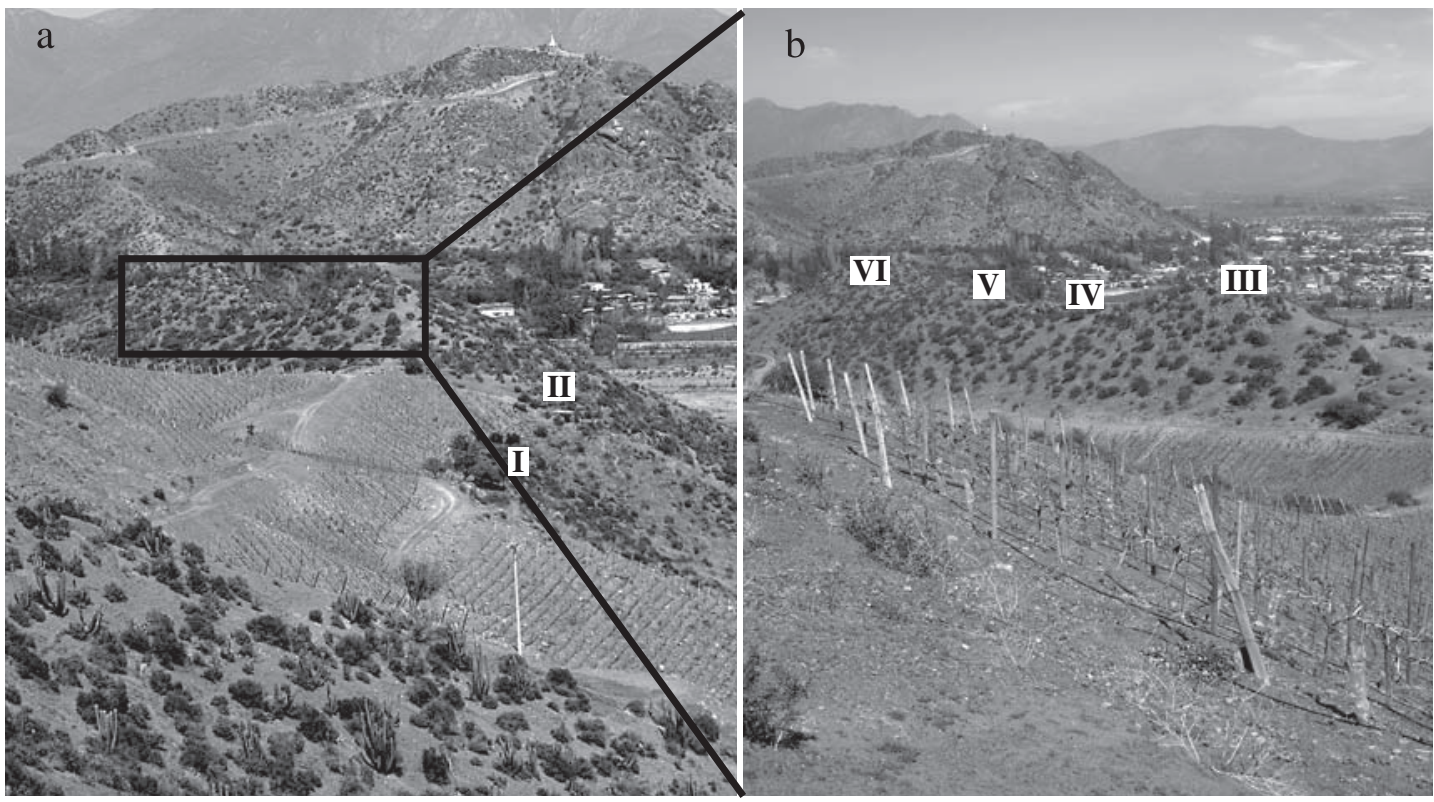

Figura 3. (a) Emplazamiento de las concentraciones I y II de arte rupestre; (b) emplazamiento de las concentraciones III a VI. (a) Location of rock art concentrations I and II; (b) Location of rock art concentrations III to VI.

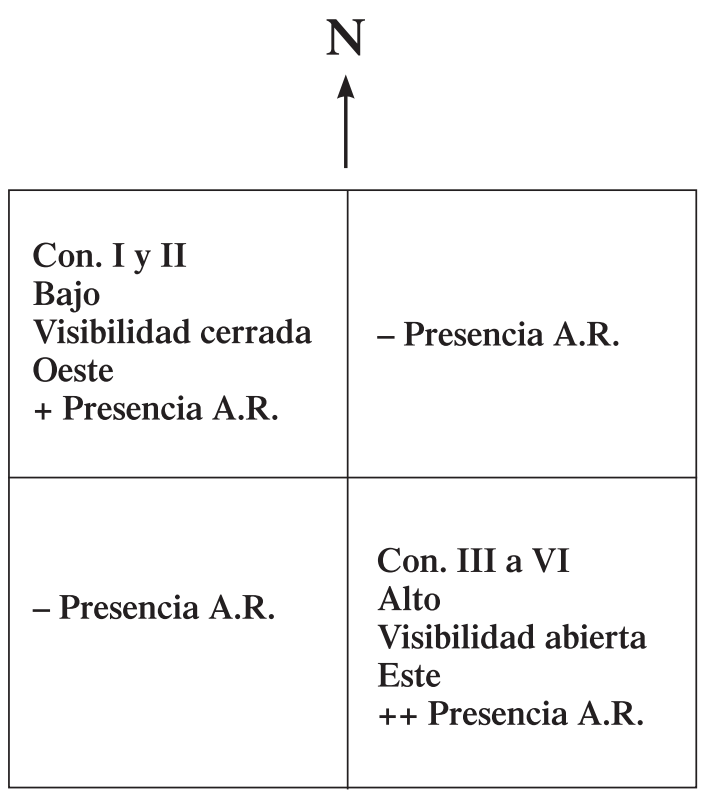

Figura 4. Sistema de organización cuatripartito en cerro Paidahuen.

System of quadripartite organization at Paidahuen hill.

\section{Quinta estructuración espacial: tripartición}

La identificación de las estructuras previas en la organización del arte rupestre de Paidahuen se ha basado únicamente en los atributos espaciales de la distribución de los bloques con grabados, considerando atributos de emplazamiento, cuantitativos y presencia/ausencia de éstos. Pero, también, al interior de los diseños (que son uno de los elementos de significación esencial del arte rupestre) se encuentra un patrón espacial del mismo tipo. Aunque los petroglifos de la cuenca superior del río Aconcagua, en general, y del sitio Paidahuen, en concreto, presentan una gran heterogeneidad en sus diseños, existen representaciones de rostros humanos que poseen un patrón discernible.

Este diseño es bastante escaso en el sitio, pues solamente existen tres casos, soportes: 164 (concentración I), 90 (concentración III) y 29 (concentración VI) (Figura 7). El soporte 164 se ubica en la primera concentración del sitio, lo que correspondería a su extremo septentrional (Figura 7a). Luego, el soporte 90 se dispone en una concentración que es en sí misma un umbral, la concentración III, que es donde se produce la inflexión en la segunda estructura (dualidad) y que es la base para la posterior conformación de la tercera estructuración correspondiente a la cuatripartición (Figura 7b). Finalmente, el soporte 29 se dispone en la última concentración de arte rupestre, correspondiente al extremo meridional del sitio (Figura 7c).

El hecho de contar con sólo tres diseños de rostros implicaría que cualquier análisis de su distribución espacial devendría en tripartición. Pese a ello, pensamos que esta quinta estructuración es 
a
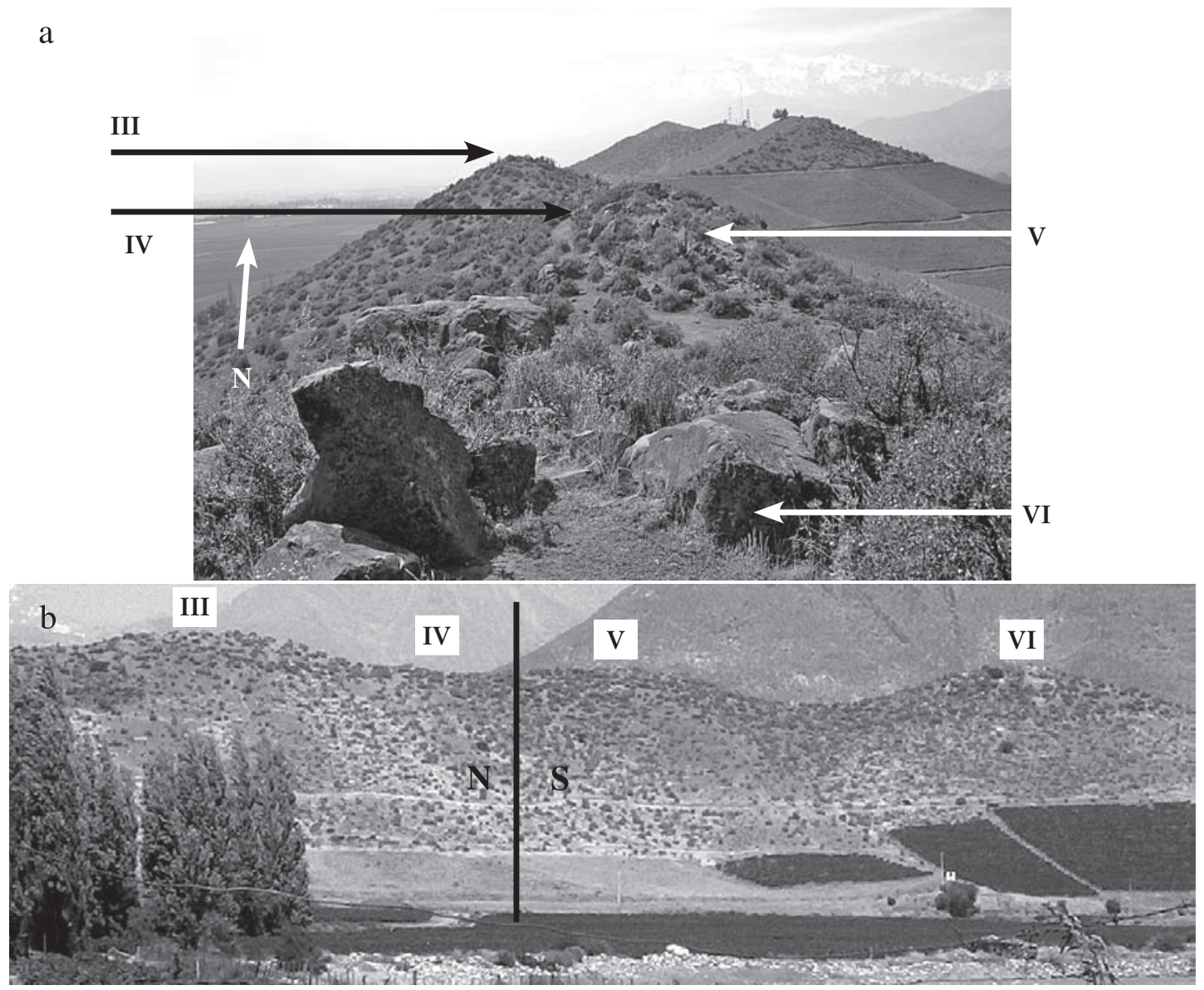

Figura 5. (a) Visión desde el sur de las concentraciones III a VI; (b) visión desde el oeste de las concentraciones III a VI y relieves en los que se emplazan.

(a) View from the South of rock art concentrations III to VI; (b) View from the West of rock art concentrations III to VI and relief in which are they located.

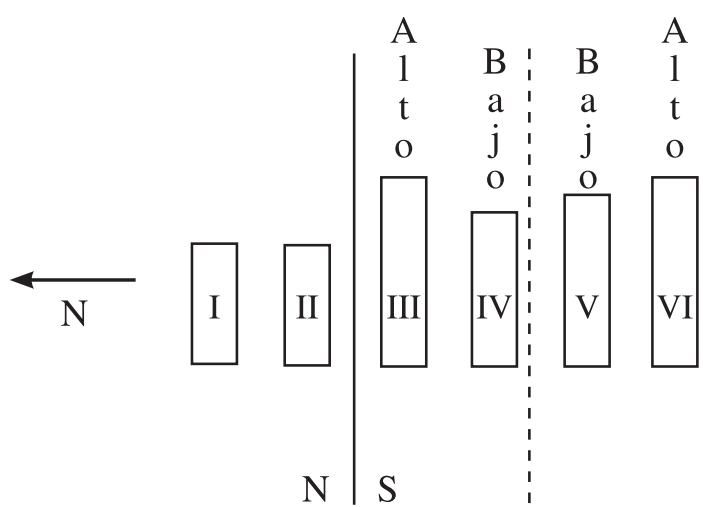

Figura 6. Esquema que grafica la cuarta operacionalización de la estructura espacial del sitio, con oposición entre concentraciones y altura relativa de las cumbres del cerro.

Schematic representation of the fourth operationalization of spatial structure of the site, with opposition between the concentrations and their height relative to the peaks of the hill. válida porque los diseños no se disponen de forma aleatoria en el espacio, sino que, al contrario, se sitúan en tres puntos centrales a la organización del sitio: en su inicio (concentración I); en el lugar donde se produce la inflexión que define la segunda y tercera estructura espacial (concentración III); y en el término del sitio (concentración VI). Por ello, estos rostros se constituyen en un diseño ancla que articula la totalidad de los sectores del sitio a través de su presencia.

\section{Discusión}

Los hechos presentados permiten discutir varios temas centrales: las posibilidades de los códigos espaciales (nivel teórico-metodológico), la interpretación de los códigos (nivel interpretativo) y su implicancia para el conocimiento de las 

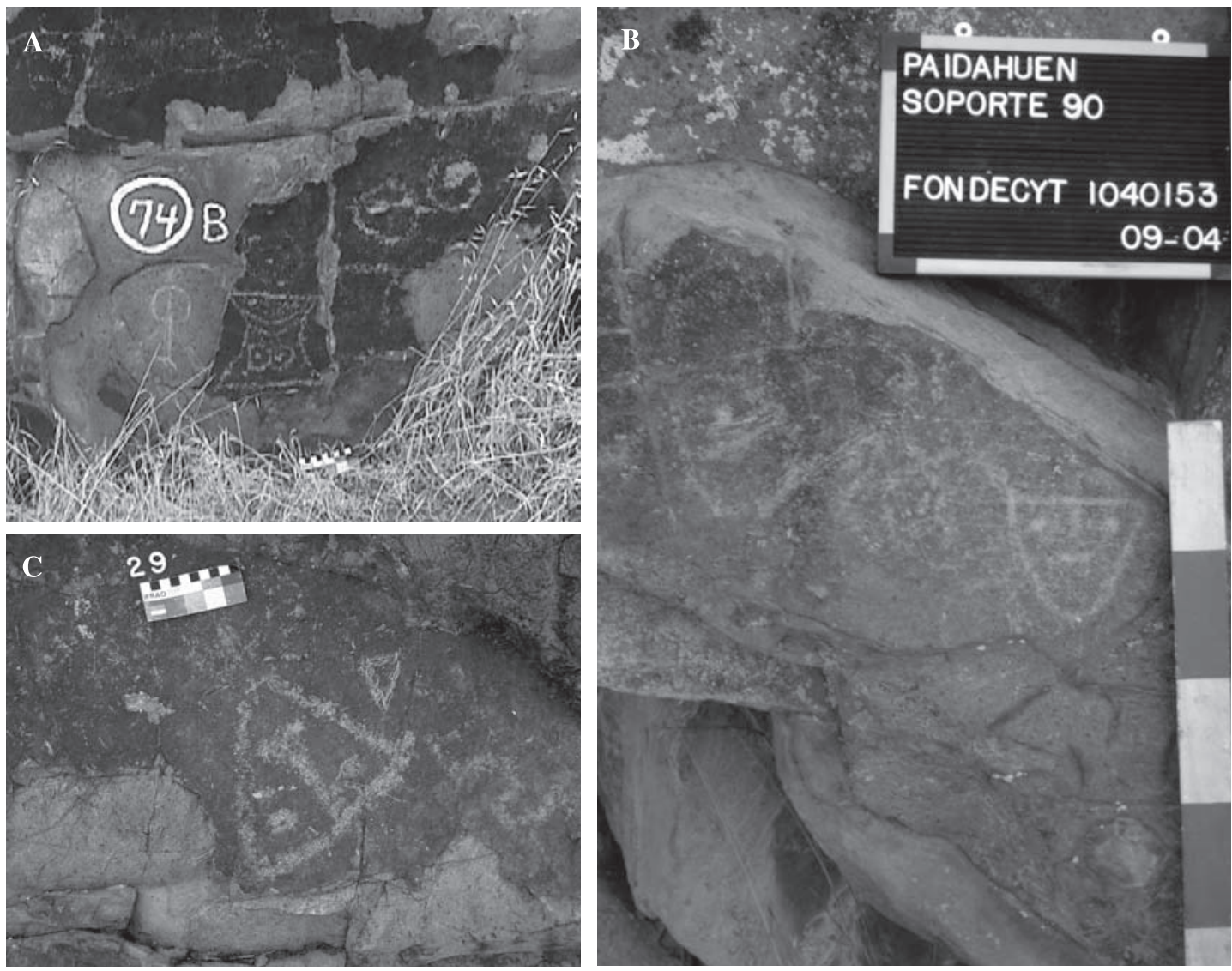

Figura 7. Diseños de rostro en sitio Paidahuen. (a) Soporte 164 (concentración I); (b) Soporte 90 (concentración III); (c) Soporte 29 (concentración VI).

Face designs in Paidahuen site. (a) Rock engraving 164 (concentration I); (b) Rock engraving 90 (concentration III); (c) Rock engraving 29 (concentration VI).

poblaciones prehispánicas de Chile central (nivel prehistórico).

Las posibilidades del código espacial es el tema esencial de este artículo, pues de su factibilidad deriva este trabajo y es posible avanzar en otras interpretaciones del sitio.

Las estructuraciones espaciales observadas no vienen condicionadas por la disponibilidad de rocas. Esta observación derivó del conteo de los bloques que presentaban condiciones propias para ser grabadas, pero no tenían petroglifos. Con el fin de evitar las subjetividades de estas definiciones, tal discriminación se realizó al finalizar el relevamiento del arte rupestre, de manera tal que se tenía ya un conocimiento claro de los atributos que definían a los bloques con grabados. El resultado de este ejercicio fue reconocer centenares de bloques factibles de ser grabados, pero que no tenían petroglifos y que se distribuían por distintos espacios de este relieve, por lo que en forma alguna es posible pensar que esta estructuración sea aleatoria y determinada por la disposición natural de las piedras.

En el mismo sentido, las características estructurales del arte rupestre del sitio Cerro Paidahuen -tipos de rocas utilizadas, tamaños, orientaciones de los paneles, cantidad de figuras por bloquesmuestran una homogeneidad significativa que se reproduce en la comentada reiteración del patrón de organización interna de cada una de las concentraciones (ver también Troncoso 2006), por lo que tales variables no afectan en modo alguno las estructuraciones propuestas.

Asimismo, los análisis se orientaron a considerar la variabilidad espacial del arte rupestre en dos niveles complementarios. El primero centrado en la distribución de los bloques con grabados al 
interior del sitio, evaluando su distribución espacial a partir de criterios de frecuencia que consideraron su relación con los respectivos campos de visibilidad y emplazamiento en el cerro. El carácter significativo de tales variables descansa en el supuesto básico que esbozamos al iniciar este trabajo: la naturaleza espacial del arte rupestre implica que su variabilidad espacial es central para el reconocimiento de estos códigos y la interpretación de este tipo de materialidad. En tal sentido, y considerando la amplia disponibilidad de rocas para ser modificadas al interior del cerro, pensamos que los cambios en los campos de visibilidad y en los relieves en los que se emplazan los petroglifos responden a elecciones espaciales particulares ${ }^{3}$.

El segundo nivel de este análisis utilizó la variabilidad espacial de los petroglifos, examinada a partir de uno de los pocos diseños estandarizados en el sitio: los rostros. Al respecto, las características de las normas semióticas que definen este arte rupestre implican la realización de diseños ampliamente variados, de carácter básicamente no figurativo, y donde es complejo establecer tipologías que sistematicen las imágenes y posibiliten su comparación. Es por ello que se recurrió a uno de los pocos diseños estandarizados y de fácil reconocimiento, el rostro.

La combinación de estos dos niveles funciona de manera coherente en el esquema propuesto pues, por un lado, el eje central definido es de tipo espacial y, por otro, la presencia de estos principios de ordenación debería fundarse en su reiteración a diferentes niveles (Criado 1999, 2000a) y en

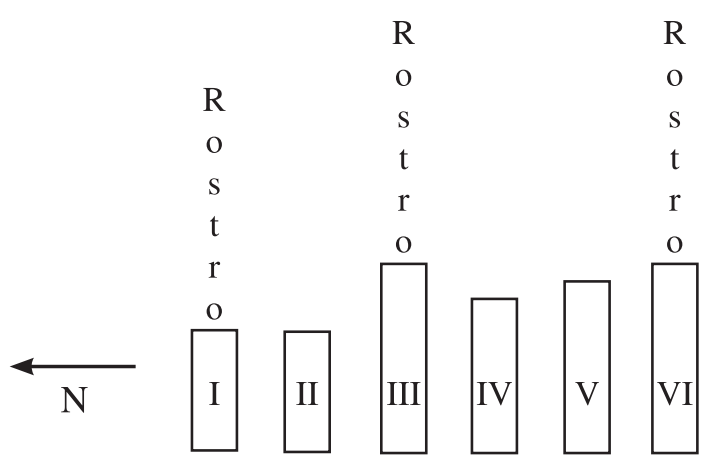

Figura 8. Esquema que grafica la quinta operacionalización de la estructura espacial del sitio, con tripartición dada por la distribución de los diseños con rostro.

Schematic representations of the fifth operationalization of spatial structure of the site, with tripartition produced by the distribution of face designs at the site. su combinación para dotar de significado a este espacio (Eco 1990).

Otro aspecto significativo para reconocer estos códigos espaciales se refiere a las características de estas estructuraciones. Nos encontramos aquí con que, primero, estructuraciones duales y cuatripartitas de similares características han sido reconocidas para otros sitios del área de estudio (Troncoso 2006, 2007), remitiéndose a un mismo patrón de oposición norte-sur, con primacía de esta segunda sobre la primera ${ }^{4}$. Segundo, al analizar la estructura dual en Paidahuen, vemos que los tres aspectos donde ella se reproduce siguen un patrón similar, primacía del sur por el norte, reproduciéndose una misma lógica en niveles diferentes (Troncoso 2006, 2007). Tercero, estructuraciones similares han sido reconocidas para la decoración de la cerámica de los períodos Intermedio Tardío y Tardío en nuestra zona de estudio (Pavlovic 2006; Pavlovic et al. 2003), lo que sugiere una compatibilidad estructural entre diferentes ámbitos fenoménicos de las expresiones materiales de las poblaciones del área de estudio (Criado 1999).

La interpretación de los códigos espaciales se constituye en un paso central tras la identificación formal de estas estructuraciones espaciales, posibilitando dotar de sentido una organización específica. En particular, el conjunto de estructuraciones espaciales reconocidas son coherentes y congruentes con los esquemas de organización espacial descritos, previamente, para el Tawantinsuyu (p.ej., Morris y Thompson 1985; Pärssinen 2003; Pease 2000; Wachtel 1976; Zuidema 1991, 1995). Como lo han indicado estos autores, el análisis de diversos ámbitos fenoménicos del Estado Incaico ha mostrado cómo los principios de dualidad, tripartición y cuatripartición se constituyen en elementos que estructuran sus organizaciones espaciales: comenzando con la decoración cerámica, continuando con la organización de sitios arqueológicos como Huanuco Pampa y finalizando con la organización de sus provincias, la espacialidad de los grupos sociales que habitaban el Cusco, la identidad de las parcialidades sujetas al estado e, inclusive, los lazos de parentesco (p.ej., Julián 2002; Pease 2000; Wachtel 1976; Zuidema 1991, 1995). Así estos principios se constituyen en verdaderos códigos espaciales incaicos.

En el caso que nos interesa, encontramos cómo ellos se expresan y materializan en un ámbito fenoménico completamente desconocido hasta el momento, 
el arte rupestre. Inclusive, al analizar detalladamente la estructuración cuatripartita que se encuentra en Paidahuen, vemos que esta se ajusta de manera exacta al patrón de organización del Tawantinsuyu y sus provincias, pues se estructura a partir de un juego de opuestos y jerarquías por el cual se definen cuatro grandes provincias: Chinchasuyu, asociado a arriba e izquierda; Antisuyu, arriba y derecha; Collasuyu, abajo y derecha, y Contisuyu, abajo e izquierda. Lo interesante es que en esta organización incaica, Chinchasuyu, se opone y predomina sobre Antisuyu, mientras que Collasuyu se opone y predomina sobre Contisuyu. Igualmente, eso genera un sistema de oposiciones y predominios que es compatible con la estructuración espacial que define la cuatripartición del cerro Paidahuen tomando como criterio la frecuencia y distribución del arte rupestre (Figura 9).
En Paidahuen se materializa, por lo tanto, un concepto de espacio fundado en la fusión de una serie de códigos particulares propios al Estado Inca, tal como son la dualidad, la tripartición y la cuatripartición. Sin embargo, estos principios no son exclusivos al Tawantinsuyu, ya que conforman códigos centrales a la cosmovisión andina que, aparentemente, se retrotraen hasta épocas previas a la irrupción del Estado Incaico y se proyectan hasta tiempos actuales en las sociedades indígenas andinas (p.ej., Harris y Bouysse-Cassagne 1988; Mariscotti 1978; Moore 1995; Platt 1976; Wachtel 1976).

De este modo, podemos sugerir que en Paidahuen se materializan códigos espaciales propios del pensamiento andino tal, y como han sido definidos, por un conjunto de investigadores del área. Obviamente, esta proposición podría ser cuestionada dados sus supuestos esencialistas, ahistóricos y negadores

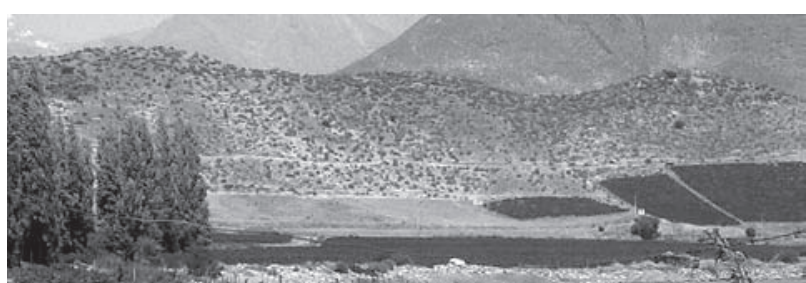

Cerro Paidahuen

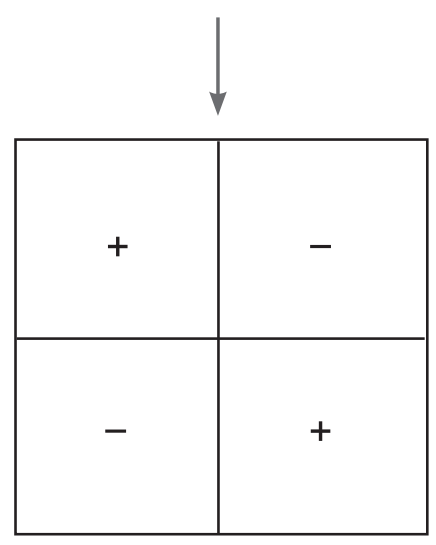

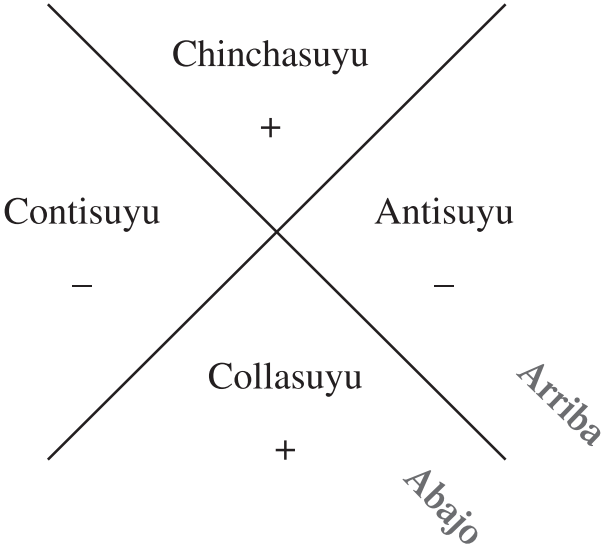

Tawantinsuyu

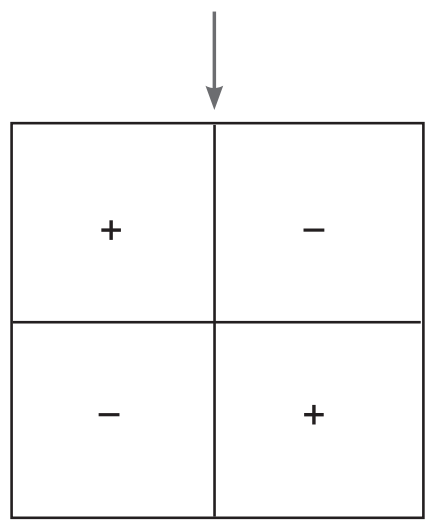

Figura 9. Comparación esquemática entre la lógica de la cuatripartición del Tawantinsuyu y el sitio cerro Paidahuen. Schematic comparison between the quadripartite logic of Tawantinsuyu and the Paidahuen site. 
de la variabilidad al interior de las sociedades indígenas de los Andes. Pero, a pesar del regusto postmoderno de una visión de este tipo, centrada en la fragmentación social y la negación de metarrelatos ${ }^{5}$ (Jameson 1991; Lyotard 1984), no creemos que se pueda aplicar esta autocrítica al presente caso de estudio por las siguientes razones: (i) evidencias arqueológicas, etnográficas y etnohistóricas para diferentes poblaciones andinas muestran que estos principios estructurales se reiteran en diferentes grupos andinos (p.ej., Berenguer 2000; Burger 1992; González 1998; Harris y Bouysse-Cassagne 1988; Kolata y Ponce Sanginés 1992; Mariscotti 1978; Pease 2000; Wachtel 1976; Zuidema 1995); (ii) el reconocimiento estructural de estos códigos y su asociación con una cosmovisión andina no niega la historicidad, ni la variabilidad de estos grupos; simplemente, señala la presencia de un elemento estructural común. Los contenidos, así como las configuraciones sociales de las poblaciones que los construyeron, pueden variar a partir de esa estructura. Sin embargo, lo interesante es cómo bajo esa posible variabilidad existen modos similares de conceptualizar y organizar el espacio, códigos que estructuran en última instancia los patrones de pensamiento; (iii) como se desprende del punto anterior, el reconocimiento de estos principios estructurales y la caracterización de los contenidos y configuraciones de los distintos grupos humanos en los que éstos se materializan, son dos niveles de análisis diferentes, aunque complementarios, por lo que uno no niega a otro.

Finalmente, algunas implicancias para la prehistoria de Chile central se desprenden de la discusión previa. Si reconocemos que en Paidahuen se materializan estos conceptos andinos, podemos señalar que la producción del arte rupestre se remite y ajusta a códigos compartidos por poblaciones humanas en diferentes sectores de los Andes, conformando una estructura de cosmovisión similar, no obstante las particularidades y diferencias de contenido posibles de reconocer en su eje de variación sincrónico y diacrónico.

Considerando que el Estilo II de arte rupestre de la cuenca superior del río Aconcagua ha sido adscrito al período incaico (Troncoso 2005), estos resultados en primera instancia no deberían impresionarnos demasiado, ya que la cronología es compatible con la interpretación (como lo requiere la argumentación arqueológica convencional). Sin embargo, hemos de reconocer que patrones como los aquí descritos no han sido identificados para sitios de arte rupestre de otros sectores del Tawantinsuyu, lo que es esperable, dada la ausencia de aplicación de enfoques teóricometodológicos similares a los de este trabajo.

Pero, por otro lado, el Estilo I reconocido en Paidahuen ha sido adscrito al período inmediatamente anterior, Intermedio Tardío, por lo que nuestros resultados implican que en este momento ya se materializan en el espacio local los códigos propios a la forma de pensamiento andino descrita (o identificada) en momentos históricos posteriores.

La evidencia encontrada en Paidahuen no es en ningún caso aislada, sino que puede ser sumada a la de otros investigadores (p.ej., Durán et al. 1991; Hidalgo 1989; Latcham 1926; Sánchez 1993, 1995, 2004; Thomas y Massone 1994), quienes desde otras perspectivas centradas básicamente en el análisis de los patrones decorativos y cementerios sugerían la presencia de una estructura andina en el registro arqueológico de Chile central previo a la llegada del Inca. En este caso, cerro Paidahuen, a su vez que abre nuevos caminos para interrogar al arte rupestre, da cuenta de tal estructuración a un nivel espacial, entregando nuevos antecedentes para continuar el debate sobre la naturaleza andina de las poblaciones del período Intermedio Tardío en esta zona de Chile.

\section{Conclusiones}

Este trabajo partió del reconocimiento de la naturaleza espacial del arte rupestre para proponer que su distribución se remite a patrones estructurales que ordenan su inscripción no sólo a nivel regional o macro, sino también al interior del sitio arqueológico (o nivel semimacro sensu Troncoso 2008). Mientras la primera de estas escalas ha sido ampliamente explorada, la segunda de ellas sigue siendo apenas esbozada.

La importancia de este reconocimiento radica en la factibilidad de que los sitios de arte rupestre no sólo materializan un conjunto de códigos espaciales que posibilitan acercarse al concepto de espacio de sus poblaciones, sino que a través de la modificación de las rocas establecen una arquitectura particular. Pero esta arquitectura y la expresión de estos códigos espaciales no radican únicamente en la creación de grabados, sino más bien en la articulación necesaria y significativa que se establece entre el entorno inmediato en el que se ubica cada bloque de arte rupestre y cada una de 
las concentraciones de petroglifos. De este modo, el cerro Paidahuen, sus distintos relieves, las rocas grabadas, su emplazamiento y las rocas no grabadas conforman una totalidad compleja y sintáctica que da origen y sentido a la materialización de esta estructura espacial particular.

La reconstrucción de estos códigos, lejos de ser una simple imposición de los investigadores sobre el objeto de estudio, emerge del uso de criterios objetivables y contrastables en el registro arqueológico, donde la variabilidad espacial y los campos de visibilidad se constituyen en atributos anclas. La fuerza de su condición de realidad descansa, también, en la recurrencia de estos códigos en distintas materialidades del período Tardío e Intermedio Tardío y en diferentes ámbitos fenoménicos (Criado 1999). En esa línea, si bien los principios de dualidad, cuatripartición y tripartición, han sido reconocidos para diferentes ámbitos de la materialidad incaica, éste es el primer registro de su presencia en un ámbito muy poco explorado, el arte rupestre. En esta manifestación nunca han estado presentes las discusiones sobre las estructuras del pensamiento incaico y, por qué no decirlo, de los aspectos simbólicos de las llamadas poblaciones andinas (para algunas excepciones ver en Chile, Espinosa 1996; Martínez y Berenguer 1986).

El reconocimiento de estos códigos es, a la postre, significativo para aproximarnos a una historia prehispánica de los sistemas de pensamiento que posibilita el descubrimiento de compatibilidades y diferencias, tanto a nivel sincrónico como diacrónico, entre las distintas poblaciones que ocuparon el llamado mundo andino. Ahora bien, debemos precisar que, evitando toda tentación y riesgo de esencialismo andinista, el resultado de nuestro trabajo muestra la presencia, a través de su materialización en el arte rupestre, de un modelo de racionalidad espacial que coincide bien con el que histórica y etnohistóricamente ha sido definido para el mundo incaico. Pero esto no quiere decir que sean el mismo, deriven uno de otro o ambos del mismo origen, y sobre todo funcionen igual. La significación histórica de esta recurrencia estructural permanece, pues, como un problema que otras investigaciones tendrán que debatir. Nuestro trabajo sólo aporta una hipótesis estructural para contribuir a ese debate.

Sin embargo, y esbozando una interpretación de este código desde tal horizonte de inteligibilidad, una revisión del conjunto de sitios de arte rupestre en la cuenca superior del río Aconcagua muestra que más allá de la recurrencia de la organización dual y tripartita en varios de ellos (Salatino 2008; Troncoso 2006), la cuatripartición se reitera sólo en otros dos grandes conjuntos de sitios (Casa Blanca y Tuququre), que son a su vez los sitios donde se presentan mayores cantidades de rocas intervenidas (Salatino 2008; Troncoso 2006). Esta diferencia en la inscripción espacial de los códigos nos parece significativa, pues establece una heterogeneidad entre los sitios de la localidad, diferencia que puede ser pensada desde el sentido mismo que tiene este código espacial en el mundo andino: la cuatripartición es el lugar de la unión de los opuestos, un espacio de mediación o taypi en el que se establece la fundación del mundo (Cereceda 1988), construyendo a estos lugares como sendos espacios sagrados y rituales de las poblaciones locales.

De esta forma, el reconocimiento de estos códigos permite abrir espacios para comenzar a esbozar hipótesis interpretativas para la comprensión de las dinámicas pasadas de las comunidades prehispánicas, comprendiéndolas desde la aplicación de un modelo de inteligibilidad andino ${ }^{6}$; interpretación que al basarse en un horizonte completamente diferente permite plantear, de una u otra manera, el problema político de toda producción de conocimiento en Arqueología: la reproducción de nuestro modelo de racionalidad.

Agradecimientos: A Daniel Pavlovic y Rodrigo Sánchez, compañeros de investigación. A todos aquellos que colaboraron en el registro del sitio cerro Paidahuen: Patricia Barría, María José Barrientos, Constanza Gnecco, Katherine González, Pablo Larach, Marco Portilla, Joaquín Vega y Francisco Vergara. Al Museo Chileno de Arte Precolombino que patrocina este proyecto. Al Consejo Nacional de Ciencia y Tecnología que financia esta investigación por medio de los siguientes proyectos: Fondecyt 1040153, Cooperación Internacional 7040002 y al Ministerio Ciencia e Innovación del Gobierno Español que financia el proyecto ContextAR2HUM2005-01119 y el CSD TCP 2007-00058. A los evaluadores de este artículo por sus comentarios que permitieron mejorar este trabajo, así como a los editores de Chungara Revista de Antropología Chilena por sus recomendaciones editoriales. 


\section{Referencias Citadas}

Bender, B.

1998 Stonehenge, Making Space. Berg, Londres.

Bender, B. y L. Winter

2001 Contested Landscapes: Movement, Exile and Place. Berg, Londres.

Berenguer, J.

2000 Tiwanaku, Señores del Lago Sagrado. Museo Chileno de Arte Precolombino, Santiago.

Burger, R.

1992 The sacred center of Chavin de Huantar. En The Ancient Americas: Art from Sacred Landscapes, editado por R. Townsend, pp. 265-277. The Art Institute of Chicago, Chicago.

Cereceda, V.

1988 Aproximaciones a una estética andina: de la belleza al tinku. En Raíces de América, El Mundo Aymara, editado por X. Albo, pp. 283-363. Alianza Editorial, Madrid.

Cobas, I.

2003 Formas de representar, mirar e imaginar: metodología para el estudio de la decoración geométrica en la prehistoria reciente. En Arqueología e Iconografía: Indagar en las Imágenes, editado por T. Tortosa y J. Santos, pp. 17-39. L'erma di Bretschneider, Roma.

Cobas, I. y P. Prieto

1998 Regularidades espaciales en la cultura material: la cerámica de la edad del Bronce y la edad del Hierro en Galicia. Arqueología Espacial 17:151-175.

Criado, F.

1993 Visibilidad e interpretación del registro arqueológico. Trabajos de Prehistoria 50:39-56.

1999 Del terreno al espacio: planteamientos y perspectivas para la Arqueología del Paisaje. TAPA 6.

2000a Problems, functions and conditions of archaeological knowledge. Journal of Social Archaeology 1:126-146.

2000b Walking abour Lévi-Strauss: Contributions to an archaeology of thought. En Philosophy and Archaeological Practice, editado por C. Holtorf y H. Karlsson, pp. 277-304. Bricoleur Press, Gotemburgo.

2005 Arqueológicas: la razón perdida. Manuscrito en posesión del autor.

Chippindale, C. y G. Nash, editores

2004 The Figured Landscapes of Rock Art: Looking at Pictures in Place. Cambridge University Press, Cambridge.

Durán, E., M. Massone y C. Massone

1991 La decoración Aconcagua: algunas consideraciones sobre su estilo y significado. Actas del XI Congreso Nacional de Arqueología Chilena, tomo I, pp. 61-87. Santiago.

Eagleton, T.

1997 Las Ilusiones de la Posmodernidad. Ediciones Paidós, Barcelona.

2005 Después de la Teoría. Ediciones Debate, Barcelona.

Eco, U.

1990 Semiótica y Filosofía del Lenguaje. Editorial Lumen, Barcelona.

Espinosa, G.

1996 Lari y Jampatu, ritual de lluvia y simbolismo andino en una escena de arte rupestre de Ariquilda 1, Norte de Chile. Chungara 28:133-157.

Godelier, M.

1989 Lo Ideal y lo Material. Ediciones Taurus, Madrid.
González, P.

1998 Doble reflexión especular en los diseños Diaguita-Inca (1470-1536 d.C.), de la imagen al símbolo. Boletín Museo Chileno de Arte Precolombino 7:39-52.

Harris, O. y T. Bouysse-Cassagne

1988 Pacha, en torno al pensamiento aymara. En Raíces de América, el Mundo Aymara, editado por X. Albó, pp. 271281. Alianza Editorial, Madrid.

Hidalgo, J.

1989 Diaguitas chilenos protohistóricos. En Prehistoria: Culturas de Chile, editado por J. Hidalgo, V. Schiappacasse, H. Niemeyer, C. Aldunate e I. Solimano, pp. 289-293. Editorial Andrés Bello, Santiago.

Jameson, F.

1991 El Posmodernismo o la Lógica Cultural del Capitalismo Avanzado. Ediciones Paidós, Barcelona.

Julián, C.

2002 Identidad étnica y filiación por suyu en el imperio Incaico. Boletín de Arqueología PUCP 6:11-22.

Kolata, A. y C. Ponce Sanginés

1992 Tiwanaku: The city at the center. En The Ancient Americas: Art from Sacred Landscapes, editado por R. Townsend, pp. 317-334. The Art Institute of Chicago, Chicago.

Latcham, R.

$1926 \mathrm{El}$ culto al tigre entre los antiguos pueblos andinos. Revista Chilena de Historia Natural 30:19-22.

Leroi-Gouhran, A.

1983 Los Primeros Artistas de Europa: Introducción al Arte Parietal Paleolítico. Ediciones Encuentro, Madrid.

1994 Las Religiones de la Prehistoria. Laerte, Barcelona.

Lyotard, F.

1984 La Condición Posmoderna. Ediciones Cátedra, Madrid.

Mariscotti, A.M.

1978 Pachamama Santa Tierra, Contribución al Estudio de la Religión Autóctona en Los Andes Centro-Meridionales. Gebr. Mann Verlag, Berlin.

Martínez. J.L. y J. Berenguer

1986 El río Loa, el arte rupestre de Taira y el mito de Yakana. Boletín del Museo Chileno de Arte Precolombino 1:7999.

Moore, J.

1995 The archaeology of dual organization in Andean South America: A theoretical review and a case of study. Latin American Antiquity 6:165-181.

2005 Cultural Landscapes in the Ancient Andes. University Press of Florida, La Florida.

Morris, C. y D. Thompson

1985 Huаnисо Pampa: An Inca City and its Hinterland. Thames and Hudson, Londres.

Mostny, G. y H. Niemeyer

1985 Arte Rupestre Chileno. Ediciones del Ministerio de Educación, Santiago.

Nash, G., editor

2000 Signifying Place and Space, World Perspectives of Rock Art and Landscape. BAR, Oxford.

Nash, G. y C. Chippindale, editores

2002 European Landscapes of Rock Art. Routledge, London. 
Pärsinnen, $M$.

2003 Tawantinsuyu: El Estado Inca y su Organización Política. IFEA, Lima.

Pavlovic, D.

2006 La Gente del Valle de Las Rinconadas: Uso del Espacio y Tradiciones Tecnológicas Durante el Período Intermedio Tardío en el Valle del Río Putaendo, Cuenca Superior del Río Aconcagua. Memoria para optar al título de Arqueólogo. Departamento de Antropología, Universidad de Chile, Santiago.

Pavlovic, D., R. Sánchez y A. Troncoso

2003 Prehistoria de Aconcagua. Centro de Artes y Oficios El Almendral, San Felipe.

Pease, F.

2000 Los Incas. Fondo Editorial Pontificia Universidad Católica del Perú, Lima.

Platt, T.

1976 Espejos y Maíz. Centro de Investigación y Promoción del Campesinado, Bolivia.

Salatino, P.

2008 Imágenes sobre Rocas, Construcción del Paisaje Social en Chile Central. Tesis para optar al grado de Licenciada en Ciencias Antropológicas con orientación en Arqueología. Universidad de Buenos Aires, Buenos Aires.

Sánchez, R.

1993 Prácticas mortuorias como producto de sistemas simbólicos. Actas del XII Congreso Nacional de Arqueología Chilena, tomo II, pp. 263-277. Temuco.

1995 Cultura material, arte, monumentos y cuerpos en el espacio; prácticas mortuorias del Complejo Cultural Aconcagua. Actas del XIII Congreso Nacional de Arqueología Chilena, tomo II, pp. 281-290. Antofagasta.

2004 El Tawantinsuyu en Aconcagua (Chile central). Chungara Revista de Antropología Chilena 36:325-336.

Santos, M.

1998 Los espacios del arte: el diseño del panel y la articulación del paisaje en el arte rupestre gallego. Trabajos de Prehistoria 55(2):73-88.

Santos, M. y A. Troncoso

2005 Reflexiones sobre arte rupestre, paisaje, forma y contenido. TAPA 33.
Thomas, C. y C. Massone

1994 El Complejo Cultural Aconcagua: una consideración desde un enfoque estructural. Actas del II Taller de Arqueología de Chile Central. http.//www.geocities.com/actas2taller/ thomasymassone.pdf (Acceso 11 de diciembre de 2007).

Tilley, C.

1991 Material Culture and Text: the Art of Ambiguity. Routledge, Londres.

1994 A Phenomenology of Landscape. Berg, Londres. 2004 The Materiality of Stone. Berg, Londres.

Troncoso, A.

2005 Hacia una semiótica del arte rupestre de la cuenca superior del río Aconcagua, Chile central. Chungara Revista de Antropología Chilena 37:21-35.

2006 Arte Rupestre en la Cuenca del Río Aconcagua: Forma, Sintaxis, Estilo, Espacio y Poder. Tesis Doctoral, Departamento de Historia I, Santiago de Compostela.

2007 Beyond materiality, sintaxis and relationality of rock art and some of the things we call nature. Journal of Iberian Archaeology 9/10:231-244.

2008 Spatial syntax of rock art. Rock Art Research 25:3-11. 2009 Arte rupestre y alteridad del espacio en Chile central. En Crónicas sobre la Piedra, Arte Rupestre de las Américas, editado por M. Sepúlveda, L. Briones y J. Chacama, pp. 235243. Ediciones de la Universidad de Tarapacá, Arica.

Van de Guchte, M.

1999 The Inca cognition of landscape: archaeology, etnohistory and the aesthetics of alterity. En Archaeologies of Landscape: Contemporary Perspectives, editado por W. Ashmore y B. Knapp, pp. 149-168. Routledge, Oxford.

Villoch, V.

1998 Paisajes monumentales en un mismo espacio: la sierra de O Bocelo (Galicia). Arqueología Espacial 19-20:517528.

Wachtel, N.

1976 Los Vencidos: los Indios del Perú frente a la Conquista Española. Alianza Editorial, Madrid.

Zuidema, T.

1991 La Civilización Inca en Cuzco. Fondo de Cultura Económica, México.

1995 El Sistema de Ceques del Cuzco. Pontificia Universidad Católica del Perú, Lima. 


\section{Notas}

1 El horizonte de inteligibilidad es el ámbito de experiencia (conocimiento, valores, acervo, razón práctica, tecnología) desde el que se puede entender algo; el patrón de racionalidad es, en cambio, el modelo simbólico mediante el cual una sociedad enfrenta el mundo y, en interacción con éste, construye sentido sobre él; la clave de nuestra propuesta metodológica es, en vez de basar nuestra interpretación en nuestro propio horizonte de inteligibilidad moderno y académico, introducir un modelo antropológico en lugar de éste.

2 Una caracterización amplia del arte rupestre de la zona y de cada uno de los estilos se puede encontrar en Troncoso (2005).

3 Estas modificaciones, en última instancia, dan cuenta de las relaciones sintácticas diferenciales que establecen los bloques de arte rupestre con sus espacios de inserción.
$4 \quad$ En este punto no podemos dejar pasar una observación teórica de vital importancia. Si consideramos que estos códigos espaciales van de la mano con contenidos específicos de valor cultural, no creemos que ellos deban expresarse de forma rigurosa en todos los espacios dadas sus implicancias semánticas, como veremos en las conclusiones. De la misma forma, por un tema de sistemática de los datos, para la aplicación de este mismo principio al interior de un sitio creemos que se requiere una cantidad amplia de bloques con imágenes para que de esa forma este código sea un producto cultural intencional de la naturaleza espacial del arte rupestre y no resultado de la escasez de bloques.

5 Las implicancias políticas de esta noción de fragmentación y su relación con el capitalismo tardío han sido avanzadas por Eagleton (1997, 2005) y Jameson (1991).

6 Un ejemplo de la utilización de estos códigos del horizonte de racionalidad andina se encuentra en Troncoso (2006). 